\title{
Organic Sensor for the Detection of Ammonium
}

\author{
Laghlimi C, Smaini MA, Maallah R, Touzara S, El Qouatli S and Chtaini A*
}

Molecular Electrochemistry and Inorganic Materials Team, Beni Mellal Faculty of Science and Technology, Sultan Moulay Slimane University, Morocco

\begin{abstract}
The electrochemical behavior of ammonium was investigated at Ethylene Diamine Tetra-Acetic-modified carbon paste electrode (EDTA-CPE) in $\mathrm{NaCl}$ solution. A method was developed for the detection of the trace of this product, based on their redox reaction.

The redox peaks of ammonium were observed around $-0.50 \mathrm{~V}$ and $0.50 \mathrm{~V}$ (vs. SCE) in cyclic voltammetry. Experimental conditions were optimized by varying the accumulation time, EDTA loading and measuring solution $\mathrm{pH}$. Calibration plots were linear under the optimized parameters over the herbicides concentration range 0.8 and $16 \mathrm{mmol} \mathrm{L}^{-1}$, with a detection and quantification limits about $9.38 .10-7 \mathrm{~mol} \mathrm{~L}^{-1}$ and $3.21 .10-6 \mathrm{~mol} \mathrm{~L}^{-1}$, respectively.
\end{abstract}

\section{Keywords: Ammonium; EIS; SWV; EDTA; Sensors}

\section{Introduction}

Ammonium is the final product of the catabolism of proteins by living organisms, its presence in high amounts in human blood is an indicator kidney disorder, stomach bacterial infection or liver dysfunction. The presence of an excess of ammonium in the environment is an important indicator of pollution [1]. The ammonium cation, $\mathrm{NH}_{4}^{+}$, is the ionized form of ammonia, which can penetrate environmental waters as a product of anaerobic decomposition of nitrogen containing compounds or from waste streams containing ammonia [2]. The ammonium test is performed to control the toxic accumulation of ammonia. It is most commonly used to diagnose and monitor hepatic encephalopathy, a serious liver disease.

Ammonia $\left(\mathrm{NH}_{3}\right)$ is produced by the body's cells, especially the intestines, liver and kidneys. Most of the ammonia produced in the body is used by the liver to produce urea. Urea is also a waste product, but it is much less toxic than ammonia.

Ammonia is particularly toxic to the brain. It can cause confusion, lethargy, and sometimes coma. The increase in the amount of ammonia in the blood may be due to several abnormalities, such as: congestive heart failure, gastrointestinal bleeding, bleeding - usually in the upper gastrointestinal tract, genetic urea, hyperthermia, leukemia, hepatic insufficiency, muscular effort.

Several methods of analyzing ammonium have been developed, such as, High performance liquid chromatography coupled with fluorescence detector [3,4], electrochemical sensors, based on zirconium titanium phosphate ion exchanger [5], or ammonium electrode prepared by poly vinyl chloride membrane containing palmitic acid and nonactin [6] and other modified electrodes [7].

The purpose of this work is to study the applicability of cyclic, squarewave voltammetry and electrochemical impedance spectroscopy (EIS) together with carbon paste electrode (CPE) modified with EDTA in the electroanalytical determination of ammonium in $\mathrm{NaCl}$ solution.

\section{Experimental}

\section{Apparatus}

Electrochemical experiments were performed using a voltalab potentiostat (model PGSTAT 100, Eco Chemie B.V., Utrecht, The Netherlands) driven by the general purpose electrochemical systems data processing software (voltalab master 4 software). A conventional three-electrode system consisting of the EDTA-modified carbon paste working, platinum counter and SCE reference electrodes was used. The pH-meter (Radiometer Copenhagen, PHM210, Tacussel, French) was used for adjusting $\mathrm{pH}$ values.

\section{Preparation of the EDTA-CPE}

The EDTA modified carbon paste electrode (EDTA-CPE) was prepared by thoroughly hand-mixing of synthesis EDTA and graphite powder (CP) to give EDTA/CP ratios of $10,30,50$, and $80 \%$ by weight $(\mathrm{w} / \mathrm{w})$. The obtained paste was dried at room temperature then a portion of the resulting paste was grounded and packed firmly into homemade PTFE cylindrical tube (geometric area $0.1256 \mathrm{~cm}^{2}$ ) electrode. Electrical contact was established with a bar of carbon.

\section{Procedure}

The electrode, after having been washed with bidistilled water and heated at room temperature, was transferred into the sample cell $(100 \mathrm{~mL})$ (the sample was purged with pure nitrogen for 10 min). A preconcentration step was necessary; the working electrode was immersed in water sample in open circuit. The initial working procedure consisted of measuring the electrochemical response of EDTA modified carbon paste electrode in $0.1 \mathrm{M} \mathrm{NaCl}$ electrolyte at fixed concentration of ammonium. The cyclic voltammetry behavior of proposed modified carbon paste electrode was recorded from -1.5 to $1.5 \mathrm{~V}$. Optimum conditions were established by measuring the peak currents in dependence on all parameters: preconcentration time, EDTA loading and measuring solution $\mathrm{pH}$. After optimization of the voltammetric parameters, calibration graphs were obtained by varying of the ammonium concentrations. All measurements were carried out under ambient conditions.

*Corresponding author: Chtaini A, Molecular Electrochemistry and Inorganic Materials Team, Sultan Moulay Slimane University, Beni Mellal Faculty of Science and Technology, Morocco, Tel: 212661118521; E-mail: chtainia@yahoor

Received February 18, 2017; Accepted March 04, 2017; Published March 14, 2017

Citation: Laghlimi C, Smaini MA, Maallah R, Touzara S, El Qouatli S, et al. (2017) Organic Sensor for the Detection of Ammonium. J Biosens Bioelectron 8: 239. doi: 10.4172/2155-6210.1000239

Copyright: (c) 2017 Laghlimi C, et al. This is an open-access article distributed under the terms of the Creative Commons Attribution License, which permits unrestricted use, distribution, and reproduction in any medium, provided the original author and source are credited. 
Citation: Laghlimi C, Smaini MA, Maallah R, Touzara S, El Qouatli S, et al. (2017) Organic Sensor for the Detection of Ammonium. J Biosens Bioelectron 8: 239. doi: 10.4172/2155-6210.1000239

Page 2 of 3

\section{Results and Discussion}

Figure 1 illustrates the cyclic voltammograms recorded at EDTA$\mathrm{CPE}$, in $0.1 \mathrm{M} \mathrm{NaCl}$ containing or not ammonium. Two redox peaks were observed, the first one at about $-0.5 \mathrm{~V}$ in the cathodic scanning direction and the second one is the nature anodic at $0.5 \mathrm{~V}$. These two peaks are sufficiently close, suggesting that they correspond to a reversible process. This is probably the nitrification process [8], which takes place in two stages, during which the ammonium ions $\left(\mathrm{NH}_{4}^{+}\right)$are oxidized to nitrite and then to nitrate, According to the mechanism:

$$
\mathrm{NH}_{3}^{+}+2 \mathrm{H}_{2} \mathrm{O} \rightleftarrows \mathrm{NO}_{2}^{-}+7 \mathrm{H}+5 \mathrm{e}^{-} \rightarrow \mathrm{NO}_{3}^{-}
$$

The influence of the scan rate was studied with EDTA-CPE immersed for $1 \mathrm{~min}$ in $7.57 \mathrm{mmol} \mathrm{L}^{-1}$ of ammonium. Figure 2 shows the relationship between the anodic peak current and the scan rate. The peak current exhibits a linear dependence on the potential scan rate in the range from 10 to $500 \mathrm{mV} \mathrm{s}^{-1}$ indicating that the EDTA-CPE reaction is controlled by non-diffusion process (Figure 2).

\section{Optimization of experimental conditions}

In order to optimize the performance of the EDTA-CPE, for the determination of ammonium, we investigated the parameters influencing the electrochemical responses parameters, EDTA loading, $\mathrm{pH}$ and accumulation time. The influence of preconcentration time

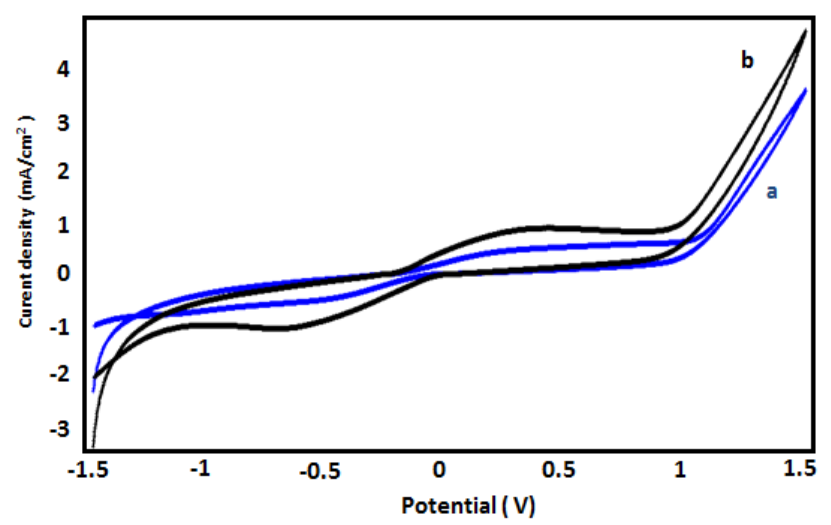

Figure 1: Cyclic voltammograms recorded for EDTA-CPE: (a) in absence and (b) in presence of $7.57 \mathrm{mmol} / \mathrm{L}$ of $\mathrm{NH}_{4}^{+}$, in $0.1 \mathrm{M} \mathrm{NaCl}$ at $100 \mathrm{mv} / \mathrm{s}, \mathrm{pH}=4$ preconcentration time $=5 \mathrm{~min}$.

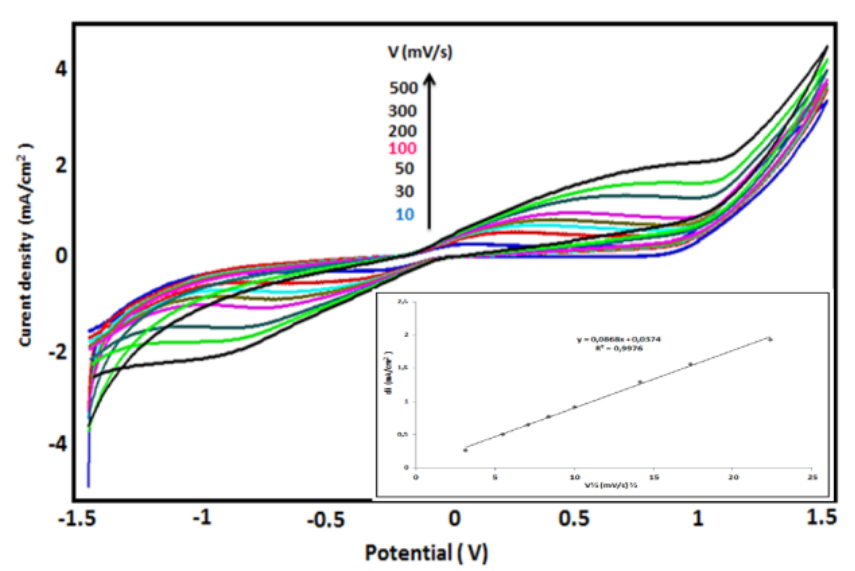

Figure 2: Cyclic voltammograms of $7.57 \mathrm{mmol} / \mathrm{L}$ ammonium at different scan rates (same conditions as for Figure 1). was examined in $7.57 \mathrm{mmol} / \mathrm{L}$ ammonium solutions, by square wave voltammetry (SWV) and EIS (Figures 3 and 4). It is clear that the high reduction peak current density is obtained for a preconcentration time of $5 \mathrm{~min}$.

Figure 4 shows the EIS recorded at EDTA-CPE, in $0.1 \mathrm{M} \mathrm{NaCl}$ containing $7.57 \mathrm{mmol} / \mathrm{L}$ of ammonium. The EIS has the form of a half circle which appears at high frequencies and corresponds to electron exchange phenomena. The diameter of the half circle corresponds to the electron transfer resistance; its minimum value is obtained for a preconcentration time equal to $5 \mathrm{~min}$. Then, the preconcentration time was fixed at $5 \mathrm{~min}$ for all further experiments.

The effect of varying $\mathrm{pH}$ on the current response of EDTA-CPE at constant ammonium concentration $(7.57 \mathrm{mmol} / \mathrm{L})$ is shown in Figure 5. As can be seen, the highest reduction peak current, is obtained at $\mathrm{pH}$ 4. The dependence of cathodic current response on the EDTA loading in the carbon paste in $\mathrm{pH} 4$ conditions is shown in Figure 6. The current response increases with the increase of amount of EDTA until EDTA/CP ratio of $10 \%$ by weight $(\mathrm{w} / \mathrm{w})$. The cathodic peaks currents decreased significantly when more than $10 \%($ EDTA, $w / w)$ is used in the electrode preparation. This probably occurs due to the conductive reduce of area of the electrode surfaces. Hence a 10\% EDTA of ratio (EDTA/CP) by weight was used throughout this work.

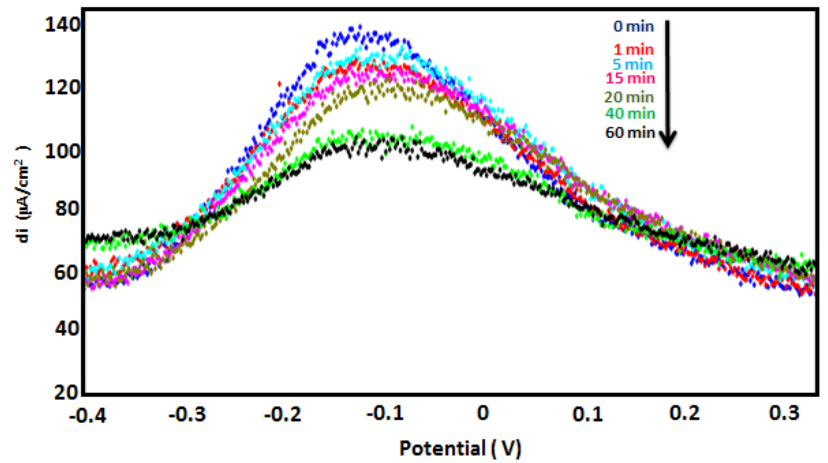

Figure 3: Square wave voltammograms (cathodic peak) recorded on EDTA $\mathrm{CPE}$, in $0.1 \mathrm{M} \mathrm{NaCl}$ containing $7.57 \mathrm{mmol} / \mathrm{L}$ of $\mathrm{NH}_{4}{ }^{+}$at different preconcentration time, scan rate $20 \mathrm{mV} / \mathrm{S}, \mathrm{pH}=7$.

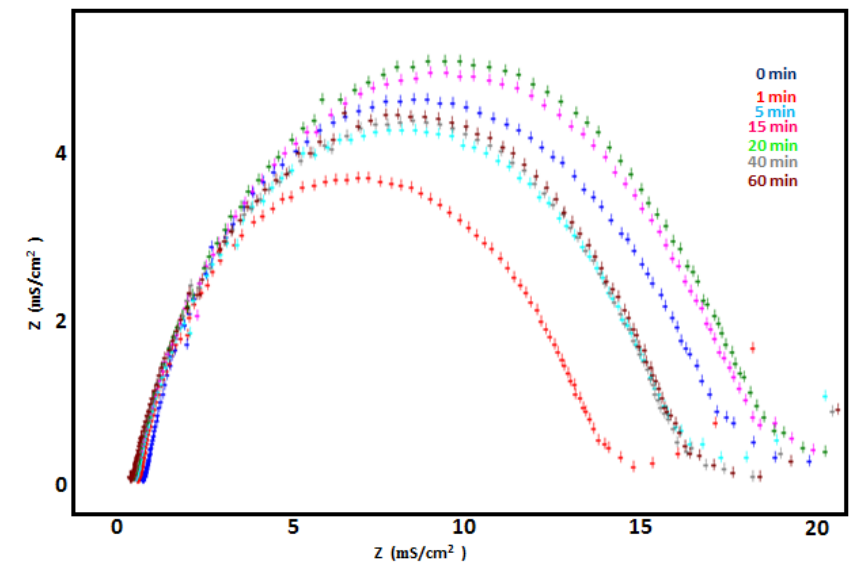

Figure 4: EIS diagrams recorded on EDTA-CPE, in $0.1 \mathrm{M} \mathrm{NaCl}$ containing 7.57 $\mathrm{mmol} / \mathrm{L}$ of $\mathrm{NH}_{4}{ }^{+}$at different preconcentration time, $\mathrm{pH}=7$. 


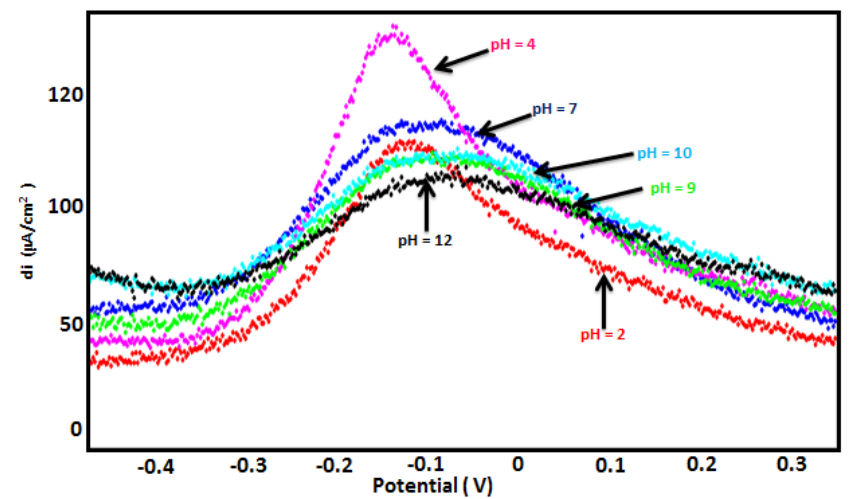

Figure 5: SWV presenting the effect of $\mathrm{pH}$ on the reduction of $\mathrm{NH}_{4}^{+}$at EDTA$\mathrm{CPE}$, in $0.1 \mathrm{~mol} / \mathrm{L} \mathrm{NaCl}$.

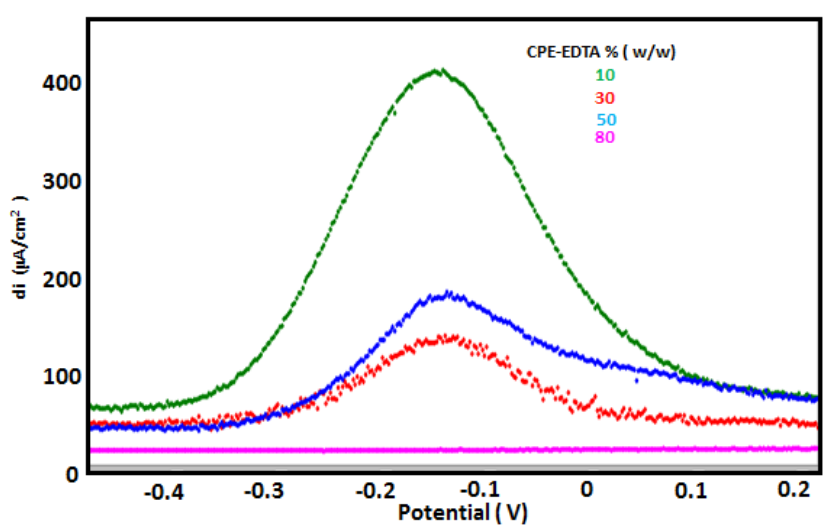

Figure 6: Square wave voltammograms recorded at EDTA-CPE at different ratios of EDTA, in $0.1 \mathrm{M} \mathrm{NaCl}$ containing $7.57 \mathrm{mmol} / \mathrm{l}$ of ammonium.

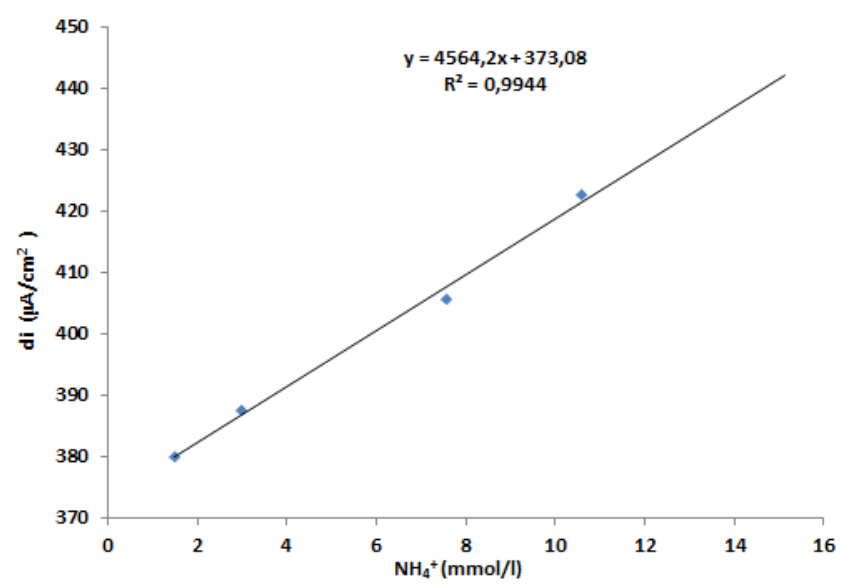

Figure 7: Plots of reduction peak area versus added concentration of $\mathrm{NH}_{4}^{+}$, in $0.1 \mathrm{M} \mathrm{NaCl}, \mathrm{pH}=4$, preconcentration time $=5 \mathrm{~min}$.

\section{Calibration graph}

The electrode response was tested for ammonium solutions in the range from 1.5 to $15.5 \mathrm{mmol} / \mathrm{L}$ under the optimal condition mentioned above. Figure 7 shows a calibration graph was then constructed from

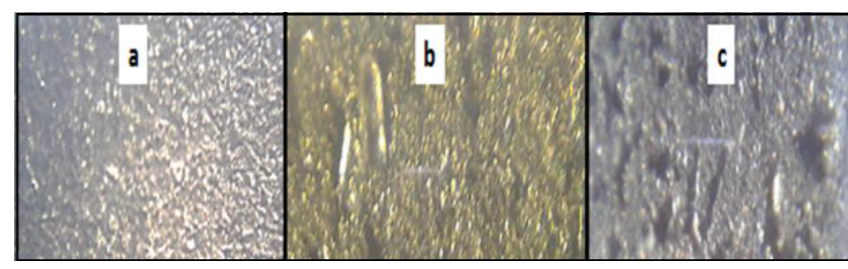

Figure 8: Images taken by optical microscopy for: a- CPE, b- EDTA-CPE after preconcentration in $\mathrm{NH}_{4}^{+}$solution.

the observed peak currents. The SWV response was linearly dependent on the concentration of ammonium. The linear regression analysis gave with a correlation coefficient of 0.9944 of reduction peak. The detection limit (DL, 3s) and quantification limit (QL, $10 \mathrm{~s}$ ) were, respectively, 9.38.10-7 $\mathrm{mol} \mathrm{L}^{-1}$ and $3.21 .10^{-6} \mathrm{~mol} \mathrm{~L}^{-1}$.

$$
p_{\text {eak }}=4564.2 \times\left[\mathrm{NH}_{4}^{+}\right]+373.08
$$

The morphology of the prepared electrode surfaces, CPE (a), EDTA-CPE (b) and EDTA-CPE after accumulating in ammonium solution (c), was studied by optical microscopy, (Figure 8 ). The organic matrix forms a homogeneous film that covers the entire surface of the carbon paste electrode. After preconcentration in an ammonium solution, we observe the formation of clusters corresponding to the complexes EDTA- $\mathrm{NH}_{4}^{+}$.

\section{Conclusion}

The proposed method for the determination of ammonium is characterized by their simplicity of preparation. The modifier is not soluble in water, non-toxic, and not a pollutant. The mixture of carbon powder and an incorporated species of EDTA were formed a homogenate paste. This last was glued strongly in the cavity of electrode. Also, there is no leaching of the electrode. The results obtained here show that the proposed SWV method is fast and sensitive.

\section{References}

1. International Organization for Standardization (1984) Water quality Determination of ammonium - Distillation and titration method. Developed by Technical Committee ISO/TC 147: Water quality. International Organization for Standardization, Geneva (Switzerland).

2. Thomas D, Rohrer J (2013) Determination of Inorganic Cations and Ammonium in Environmental Waters by lon Chromatography Using the Dionex lonPac CS16 Column. Thermo Fisher Scientific, Sunnyvale, CA, USA.

3. Laua KT, Edwards S, Diamond D (2004) Nanostructured Semiconductor Oxides for the Next Generation of Electronics and Functional Devices. Sensors and Actuators B 98: 12-17.

4. Hassan SSM, Marei SA, Badr IH, Arida HA (2001) Novel solid-state ammonium ion potentiometric sensor based on zirconium titanium phosphate ion exchanger. Analytica Chimica 427: 21-28.

5. Karakus E, Pekyardimci S, Kilic E (2006) A new potentiometric ammonium electrode for biosensor construction. Artif Cells Blood Substit Immobil Biotechnol 34: 523-534.

6. Valentini F, Biagiotti V, Lete C, Palleschi G, Wang J (2007) An Optical Based Biosensor for the Determination of Ammonium in Aqueous Environment. Sensors and Actuators B 128: 326-333.

7. Kwan RCH, Hona PYT, Renneberg R (2005) Smart Polymers and their Applications. Sensors and Actuators B 107: 616-622.

8. Bock E, Koops HP (1992) The genus Nitrobacter and related genera. In: The prokaryotes, Balows A, Trüper HG, Dworkin M, Harder W, Shleifer KH. Springer Verlag (eds), New York pp: 2302-2309. 